\title{
BMJ Open Examining the association between maternal atopy and birth outcomes using a retrospective cohort in the southeastern region of the USA
}

\author{
Ayesha Johnson, ${ }^{1}$ Thomas Mason, ${ }^{1}$ Russell S Kirby, ${ }^{2}$ Dennis Ledford, ${ }^{3}$ \\ Hamisu M Salihu ${ }^{4}$
}

To cite: Johnson A, Mason T, Kirby RS, et al. Examining the association between maternal atopy and birth outcomes using a retrospective cohort in the southeastern region of the USA. BMJ Open 2017;0:e017161. doi:10.1136/ bmjopen-2017-017161

- Prepublication history for this paper is available online. To view these files, please visit the journal online (http://dx.doi. org/10.1136/bmjopen-2017017161).

Received 10 April 2017 Revised 25 September 2017 Accepted 27 September 2017

CrossMark

${ }^{1}$ Department of Environmental and Occupational Health, University of South Florida, Tampa, Florida, USA

${ }^{2}$ Department of Community and Family Health, University of South Florida, Tampa, Florida, USA

${ }^{3}$ Departments of Internal Medicine and Pediatrics, University of South Florida, Tampa, Florida, USA

${ }^{4}$ Department of Family and Community Medicine, Baylor College of Medicine, Houston, Texas, USA

Correspondence to

Dr Ayesha Johnson;

ayesha_johnson2@yahoo.com

\section{ABSTRACT}

Objective To assess birth outcomes in primiparous women with diagnosis of non-asthmatic atopy (NAA). Researchers hypothesised that women with NAA would have reduced the risk of adverse birth outcomes compared with women without NAA. NAA is defined as having allergic rhinitis and/or atopic dermatitis.

Setting Women were mostly treated in primary care settings in South Carolina, USA.

Participants This is a retrospective cohort study in which participants were identified using a Medicaid database. Participants were primiparous women aged 19 to 25. Births occurring between 2004 and 2014 were identified using the South Carolina's Vital Statistics (VS) records of live births. Incomplete records (ie, information on plural birth, gestational age at birth or birth weight missing), plural births or infants born before completing 24 weeks of gestation were excluded. This provided 65650 complete maternal-infant dyads, representing $97.6 \%$ of the maternal records and $96.9 \%$ of the VS records. Women previously diagnosed with NAA were frequency matched 1:4 to non-atopic controls for a total of 9965 maternalinfant dyads used in the statistical analysis.

Primary outcome measures Low birth weight, small for gestational age and preterm birth.

Results Linear tests for trend were statistically significant $(p<0.001)$, indicating that NAA was associated with improved birth weight and gestational age at birth. After controlling for potential confounders, mothers with NAA had equal risk for each outcome when compared with mothers with no diagnosis of NAA.

Conclusion A diagnosis of NAA among women living in the southeastern region of the USA does not reduce the risk of adverse birth outcomes nor does it elevate the risk of same. Additional studies with more rigorous designs are warranted to confirm the findings in this study.

\section{INTRODUCTION}

The prevalence of allergic sensitisation (allergies) among children and young adults has increased since the $1940 \mathrm{~s} .{ }^{12}$ This sensitisation is associated with allergic rhinitis (AR), atopic dermatitis (AD) and asthma. ${ }^{13}$ Atopic disorders are the most common chronic diseases

\section{Strengths and limitations of this study}

Large sample size.

Very little missing data.

- Prevalence of study outcomes and other chronic disorders were consistent with the available rates in that state.

- Conducted in a single state.

- Information on the severity of each atopic disorder and information on timing of symptom onset or duration was not available.

in the developed world. ${ }^{34}$ The prevalence of $\mathrm{AD}$ has doubled or tripled in industrialised countries over the last three decades. ${ }^{45} \mathrm{AR}$ affects between $10 \%$ and $30 \%$ of the world's population. ${ }^{6} 7$ This study explores how non-asthmatic atopy (NAA), which describes $\mathrm{AD}$ and $\mathrm{AR}$, affects birth outcomes. Due to the T-helper 2 dominant immune response which occurs during pregnancy, researchers hypothesised that NAA would reduce the risk of adverse birth outcomes.

In the USA, approximately $20 \%-25 \%$ of the general adult population, between the ages of 16 and 65 years, is affected by an allergic disorder. ${ }^{8}$ While there is increasing knowledge about these disorders, the circumstances leading to the development or exacerbation of symptoms are not fully understood. Researchers have identified many environmental risk factors that can lead to the worsening of symptoms. Air quality has been identified as an important environmental risk factor in modifying symptoms of allergies. There are still questions as to whether the likelihood of developing atopic disorders increases or decreases with increased sibship. ${ }^{1011}$ There have also been ethnic and regional differences noted in the prevalence and type of atopic symptoms observed. AR and other atopic disorders affecting the nose 
and airways were more prevalent among persons living in Europe, Australia and New Zealand, ${ }^{212}$ while AD was more prevalent among persons living in African countries. ${ }^{13}$

In the past, some symptoms decreased as children matured, resulting in a smaller prevalence of atopy among adults. Younger children were more likely to experience symptoms associated with the skin such as atopic dermatitis, while older children and young adults were more likely to experience symptoms affecting the nasal passage such as allergic rhinitis. ${ }^{14}$ An argument could therefore be made that the prevalence of allergic rhinitis increased with age, which helps to explain the increased rates atopy among adults more recently when compared with previous decades. Additionally, many adults reported becoming sensitised for the first time in adulthood. ${ }^{15}$

Few studies have investigated the effects of atopic disorders on birth outcomes. Savilahti et al reported that the odds of mothers being diagnosed with AR were reduced by $50 \%$ among infants born extremely low birth weight (LBW; less than $1000 \mathrm{~g}$ ). ${ }^{16}$ Another study reported that $\mathrm{AR}$ in mothers was associated with a reduced risk of congenital abnormalities by $30 \% .^{17}$

A 2014 study conducted by Trønneset $a l^{18}$ on a Norwegian cohort of women reported that maternal atopy, not including asthma, was associated with reduced rates of preterm birth, stillbirth and neonatal death and that maternal asthma was associated with an increased risk of preterm birth. ${ }^{18}$ Asthma diagnosed in mothers increased the odds of preterm birth $15 \%$, while AR and $\mathrm{AD}$ in mothers reduced the risk of same by $16 \%$ and $10 \%$, respectively. ${ }^{18}$

Atopy in pregnant women has been associated with the overall development of the child. Croen et $a l^{19}$ reported that children whose mothers experienced atopy, including allergic rhinitis and atopic dermatitis, were at an increased risk for autism spectrum disorders. ${ }^{19}$ Maternal atopy was also reported to be with a risk factor for the development of atopy in their offspring. ${ }^{20-23}$ Studies on the effect of maternal atopy on fetal and child development have primarily focused on allergic sensitisation in the child, ${ }^{21-23}$ and fewer studies have explored the effect of NAA, that is, allergic rhinitis and/or atopic dermatitis on adverse birth outcomes in the USA.

\section{METHODS}

$\mathrm{AR}$ is a condition which is frequently underdiagnosed, and for this reason, the researchers sought to answer the research question using an administrative database as this would increase the likelihood of identifying a larger number of women with the diagnoses of interest. The study population was primiparous women aged 19-25. Women were identified retrospectively using Medicaid records from South Carolina. Birth outcomes were identified using that state's vital statistics (VS) records of live births occurring between 1 January 2004 and 1 January 2014. Incomplete records (ie, information on plural birth, gestational age at birth or birth weight missing), plural births or infants born with a gestational age at birth less than 24 weeks were excluded. This provided 65650 complete maternal-infant dyads, representing $97.6 \%$ of the maternal records and $96.9 \%$ VS records. Next, women previously diagnosed with NAA, were frequency matched 1:4 to non-atopic controls for a total of 9965 (1993 with NAA and 7972 non-atopic controls) complete maternalinfant dyads used in the statistical analysis.

Women with NAA were identified using International Classification of Diseases Ninth Revision (ICD-9) code 477 for AR and/or ICD-9 codes 691 and 692 for $\mathrm{AD}$ recorded from medical evaluations at least 1 year prior to pregnancy. Births from the women identified were linked to state birth records to classify the outcome of the pregnancy. Information on maternal characteristics that served as possible confounders was extracted from the database. These included diagnoses of hypertension and diabetes. Additional confounding demographic and risk factors including race/ethnicity and smoking were also extracted. Women were excluded from this study if they were younger than 19 years or older than 25 years, multiparous or had a plural birth. Additionally, those who gave birth before completing at least 24 weeks of gestation were excluded from these analyses. Women older than 25 years were not analysed in this study to reduce the effect that factors such as advanced maternal age or chronic conditions would have on the outcome.

The outcomes considered were LBW, small for gestational age (SGA) and preterm birth (PTB). Outcomes were defined using universal definitions. Infants were classified as LBW if their recorded birth weight was less than $2500 \mathrm{~g}$. Analysis of LBW as an outcome was restricted to infants who were born after completing 37 weeks of gestation. Gestational age was clinically estimated by ultrasonography. Infants with a birth weight that was less than 2 SD below the sex and gestational age-specific mean of the dataset were classified as SGA. Births occurring before completion of the 37 th week of gestation were classified as PTB.

Statistical analyses were conducted using STATA V.12. ${ }^{24}$ Each individual contributed a single observation (only first pregnancy) to the analysis, and therefore, standard methods for data analysis on numeric outcomes and categorical outcomes were employed. Data were summarised using univariate analysis, and bivariate associations were measured using t-tests, $\chi^{2}$ tests or Fisher's exact tests as appropriate. The independent association between prenatally diagnosed NAA status and infant outcomes were quantified by means of multivariable logistic regression models and Cox regression models.

Analysis of gestational age at birth was performed using survival analysis, where time to event was defined as each infant's clinically estimated gestational age at birth. Log-rank tests were used to measure crude associations, while a Cox regression model was built to quantify associations after accounting for the contribution of potential confounders. We tested for the non-violation of the proportionality assumption in each case. We confirmed 
this by plotting the log-negative-log of the Kaplan-Meier estimates of the survival function versus the log of time. The resulting curves were parallel.

Crude estimates from single predictor regression models were presented as well as adjusted estimates from multivariable models included all predictors (NAA, asthma, race/ethnicity, maternal smoking, gestational diabetes and prepregnancy hypertension).

This study was approved by the University of South Florida's Institutional Review Board. Permission was also obtained from the South Carolina Department of Health and Human Services to use its Medicaid and Vital Statistics records.

\section{RESULTS}

Analysis was conducted on 9965 maternal-infant dyads of which $1993(20.0 \%)$ had a diagnosis of NAA. There were 1093 (11.1\%) mothers diagnosed with AR and 959 (9.6\%) with $\mathrm{AD}$. Infants' gestational ages at birth ranged from 24 to 43 weeks with a mean and SD of 38.6 and 2.0 weeks, respectively. The mean and SD of infants' birth weight were 3155.1 and $568.4 \mathrm{~g}$, respectively.

There was a significant $(\mathrm{p}<0.001)$ increasing linear trend detected between the percentage of mothers with NAA and birth weight. Higher percentages of maternal NAA were associated with greater infant birth weight. There was also a significant $(p<0.001)$ increasing linear trend detected between the percentage of mothers with NAA and gestational age at birth. Higher percentages of maternal NAA were associated with greater gestational ages at birth. Table 1 displays sample characteristics. The sample included 4610 (46.3\%) White non-Hispanic (WNH) mothers, 4460 (44.8\%) Black non-Hispanic mothers $(\mathrm{BNH}), 802(8.0 \%)$ Hispanic mothers and 93 $(0.9 \%)$ mothers who were of another race/ethnicity or whose race/ethnicity was given as 'other'. Approximately one out of five $(19.5 \%)$ women reported smoking prior to pregnancy. Among infants born at term ( $\geq 37$ weeks), the percentage with LBW was $4.4 \%$. The percentage of infants born SGA was $2.0 \%$, while the percentage of PTB was $9.5 \%$.

There was no significant difference in the mean gestational age at birth or infant birth weight between mothers with NAA versus those without. There was also no significant association between the prevalence of NAA and study outcomes (LBW, SGA or PTB) (table 1). The Kaplan-Meier survival curves for the gestational ages at birth for infants born to mothers with a diagnosis of NAA and for those born to mothers with no diagnosis of NAA appear coincidental at almost every time point (figure 1).

The prevalence of NAA varied significantly by race/ ethnicity. NAA affected approximately $20.8 \%$ of WNH and $21.5 \%$ of BNH mothers compared with only $8.1 \%$ of Hispanic mothers and $11.8 \%$ of mothers of 'other' race/ethnicity $(\mathrm{p}<0.001)$. We noted a higher prevalence of NAA among mothers who smoked prior to pregnancy compared with those who did not $(22.2 \%$ vs $19.5 \%$;
Table 1 Bivariate analysis of NAA and study variables

\begin{tabular}{|c|c|c|c|}
\hline & $\begin{array}{l}\text { NAA present } \\
(n=1993) \\
n(\%)\end{array}$ & $\begin{array}{l}\text { Row } \\
\text { total }\end{array}$ & p Value \\
\hline \multicolumn{4}{|l|}{ Low birth weight* } \\
\hline Yes & $77(20.5)$ & 376 & \multirow[t]{2}{*}{0.795} \\
\hline No & 1730 (19.9) & 8680 & \\
\hline \multicolumn{4}{|c|}{ Small for gestational age } \\
\hline Yes & $40(20.0)$ & 200 & \multirow[t]{2}{*}{1.000} \\
\hline No & $1953(20.0)$ & 9765 & \\
\hline \multicolumn{4}{|l|}{ Preterm birth } \\
\hline Yes & $186(20.5)$ & 909 & \multirow[t]{2}{*}{0.709} \\
\hline No & 1805 (19.9) & 9051 & \\
\hline \multicolumn{4}{|l|}{ Infant sex } \\
\hline Female & $965(19.8)$ & 4866 & \multirow[t]{2}{*}{0.681} \\
\hline Male & $1028(20.2)$ & 5099 & \\
\hline \multicolumn{4}{|l|}{ Mother's race/ethnicity } \\
\hline White non-Hispanic & $960(20.8)$ & 4610 & \multirow[t]{4}{*}{$<0.0001$} \\
\hline Black non-Hispanic & $957(21.5)$ & 4460 & \\
\hline Hispanic & $65(8.1)$ & 802 & \\
\hline Other & $11(11.8)$ & 93 & \\
\hline \multicolumn{4}{|c|}{ Smoking prior to pregnancy } \\
\hline Yes & $426(22.2)$ & 1922 & \multirow[t]{2}{*}{0.008} \\
\hline No & $1564(19.5)$ & 8025 & \\
\hline \multicolumn{4}{|c|}{ Smoking during pregnancy } \\
\hline Yes & $302(20.4)$ & 1479 & \multirow[t]{2}{*}{0.665} \\
\hline No & 1690 (19.9) & 8479 & \\
\hline \multicolumn{4}{|l|}{ Prepregnancy diabetes } \\
\hline Present & $15(19.7)$ & 76 & \multirow[t]{2}{*}{0.954} \\
\hline Absent & $1978(20.0)$ & 9889 & \\
\hline \multicolumn{4}{|l|}{ Gestational diabetes } \\
\hline Present & $67(19.1)$ & 351 & \multirow[t]{2}{*}{0.664} \\
\hline Absent & $1926(20.0)$ & 9614 & \\
\hline \multicolumn{4}{|c|}{ Prepregnancy hypertension } \\
\hline Present & $41(22.2)$ & 185 & \multirow[t]{2}{*}{0.458} \\
\hline Absent & $1952(20.0)$ & 9780 & \\
\hline \multicolumn{4}{|l|}{ Asthma } \\
\hline Present & $309(100.0)$ & 309 & \multirow[t]{2}{*}{$<0.0001$} \\
\hline Absent & $1684(17.4)$ & 9656 & \\
\hline
\end{tabular}

*Among infants born after completing 37 weeks of gestation. NAA, non-asthmatic atopy.

$\mathrm{p}=0.008$ ). As expected mothers with asthma also had a higher prevalence of NAA compared with those who did not have asthma ( $100.0 \%$ vs $17.4 \%$; $\mathrm{p}<0.0001)$. Smoking during pregnancy, prepregnancy diabetes, gestational diabetes and prepregnancy hypertension were not significantly associated with NAA (table 1).

Table 2 shows the crude $\left(\mathrm{OR}_{\mathrm{C}}\right)$ and adjusted $\mathrm{OR}\left(\mathrm{OR}_{\mathrm{A}}\right)$ from Logistic regression models predicting the study 


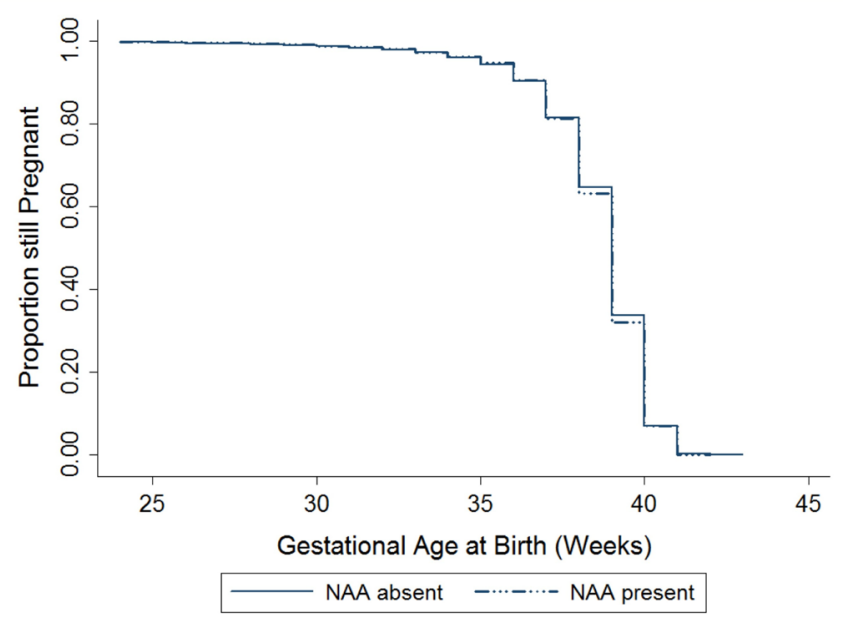

Figure 1 Kaplan-Meier curves showing gestational age at birth of infants by maternal NAA diagnosis. NAA, nonasthmatic atopy.

outcomes of LBW and SGA. Table 3 shows the crude $\left(\mathrm{HR}_{\mathrm{C}}\right)$ and adjusted $\mathrm{HR}\left(\mathrm{HR}_{\mathrm{A}}\right)$ from Cox regression models evaluating PTB. Mothers with NAA had similar odds for LBW $\left(\mathrm{OR}_{\mathrm{A}}=0.98\right)$, SGA $\left(\mathrm{OR}_{\mathrm{A}}=0.98\right)$ as mothers with no diagnosis of NAA. Mothers with NAA also had similar risk of PTB $\left(\mathrm{HR}_{\mathrm{A}}=0.99\right)$ when compared with mothers with no diagnosis of NAA.

\section{DISCUSSION}

The linear trends found in the bivariate associations along with previous literature suggest a beneficial effect of NAA on birth outcomes. This would have helped to explain the genetic presence of atopy which persists in the population, as atopy without asthma may provide a reproductive advantage for some women. However, the statistical models used in this study estimated that NAA did not significantly affect study outcomes. When NAA conditions were considered separately, neither of them (AR nor AD) were found to have any significant effect on the study outcomes. In their study, Trønnes, Wilcox, Markestad et $a l^{18}$ reported both AR and
Table 3 Cox regression models displaying the crude HR and adjusted HR for PTB

\begin{tabular}{cll}
\hline & PTB (n=9965) & \\
\cline { 2 - 3 } & $\mathbf{H R}_{\mathbf{C}}$ (95\% Cl)† & $\mathbf{H R}_{\mathbf{A}}$ (95\% Cl) \\
\hline NAA & $\mathrm{p}=0.325$ & $\mathrm{p}=0.434$ \\
No & 1.00 (Reference) & 1.00 (Reference) \\
Yes & $0.98(0.93$ to 1.02$)$ & 0.98 (0.93 to 1.03) \\
Asthma & $\mathrm{p}=0.014$ & $\mathrm{p}=0.051$ \\
No & 1.00 (Reference) & 1.00 (Reference) \\
Yes & $1.07(1.01$ to 1.13$)$ & 1.07 (0.99 to 1.11) \\
\hline
\end{tabular}

Independent variables included in adjusted models were NAA, asthma, race/ethnicity, smoking during pregnancy, gestational diabetes and prepregnancy hypertension.

${ }^{*} \mathrm{p}<0.05,{ }^{* *} \mathrm{p}<0.01,{ }^{* \star *} \mathrm{p}<0.001,{ }^{* \star *} \mathrm{p}<0.0001$.

NAA, non-asthmatic atopy; OR, adjusted OR; OR, crude OR; LBW, low birth weight; PTB, preterm birth.

$\mathrm{AD}$ to be protective against $\mathrm{PTB}(\mathrm{RR}=0.84$ and 0.90 respectively) ${ }^{18}$ however, Trønnes, Wilcox, Markestad $e t$ al ${ }^{18}$ identified AR differently. The different methods of assessing AR status may contribute to the different finding. It is also possible that geographical variation between the eastern and western hemispheres modifies the morbidity associated with atopic disorders, so that birth outcomes among women living in South Carolina and the Southeastern region of the USA are neither helped nor worsened by NAA.

The estimated prevalence of atopy (AR, AD and asthma together) found in the complete study sample was $7.20 \%$ (data not shown) which is approximately one-third the estimates given in the literature of between $20 \%$ and $25 \%$ of the general adult population aged 16 to 65 years. ${ }^{8}$ The prevalence of asthma found in the complete study sample was $4.20 \%$ (data not shown) which is approximately one-third of the estimated prevalence of $11.5 \%$ for the adult population in South Carolina. ${ }^{25}$ Estimates of NAA, that is, $A R$ and $A D$ are not available for this state. This prevalence was low even considering that this study was restricted to women between the ages of 19 and 25 years.

Table 2 Logistic regression models displaying the crude OR and adjusted OR or BW and SGA

\begin{tabular}{|c|c|c|c|c|}
\hline & \multicolumn{2}{|l|}{ LBW† (n=9017) } & \multicolumn{2}{|l|}{ SGA (n=9965) } \\
\hline & $\mathrm{OR}_{\mathrm{C}}(95 \% \mathrm{Cl}) \neq$ & $\mathrm{OR}_{\mathrm{A}}(95 \% \mathrm{Cl}) \ddagger$ & $\mathrm{OR}_{\mathrm{c}}(95 \% \mathrm{Cl}) \ddagger$ & $\mathrm{OR}_{\mathrm{A}}(95 \% \mathrm{Cl}) \neq$ \\
\hline NAA & $\mathrm{p}=0.795$ & $\mathrm{p}=0.894$ & $\mathrm{p}=0.901$ & $\mathrm{p}=0.928$ \\
\hline No & 1.00 (Reference) & 1.00 (Reference) & 1.00 (Reference) & 1.00 (Reference) \\
\hline Yes & 0.97 (0.75 to 1.25$)$ & 0.98 (0.74 to 1.30$)$ & 0.97 (0.70 to 1.42 ) & 0.98 (0.68 to 1.43$)$ \\
\hline Asthma & $p=0.618$ & $\mathrm{p}=0.847$ & $p=0.621$ & $\mathrm{p}=0.470$ \\
\hline No & 1.00 (Reference) & 1.00 (Reference) & 1.00 (Reference) & 1.00 (Reference) \\
\hline Yes & 1.16 (0.66 to 2.04$)$ & 1.07 (0.58 to 1.97$)$ & 1.25 (0.51 to 3.07$)$ & 1.42 (0.55 to 3.67$)$ \\
\hline
\end{tabular}

Independent variables included in adjusted models were NAA, asthma, race/ethnicity, smoking during pregnancy, gestational diabetes and prepregnancy hypertension.

${ }^{*} p<0.05 ;{ }^{* *} p<0.01 ;{ }^{* * *} p<0.001 ;{ }^{* * * *} p<0.0001$.

†Among infants born after completing 37 weeks of gestation.

$\pm 95 \% \mathrm{Cl}$.

NAA, non-asthmatic atopy; $\mathrm{OR}_{\mathrm{a}}$, adjusted $\mathrm{OR} ; \mathrm{OR}_{\mathrm{c}}$, crude OR; LBW, low birth weight; SGA, small gestational age. 
The prevalence was also low considering the likelihood that this population represents persons of lower socioeconomic status who are less likely to report any atopy, AR in particular. ${ }^{26-28}$ Additionally, it is quite common for AR to be both underdiagnosed and misdiagnosed ${ }^{26}$ so that the prevalence of NAA found in this study was much lower than the estimates reported in the literature. ${ }^{38}$ It is also possible that differentially diagnosing AR only takes place when a patient is experiencing severe symptoms. ${ }^{29}$ Additionally, there can be wide variations in the severity of symptoms preceding diagnosis as well as wide regional and seasonal variation in prevalence rates. While the prevalence of the atopic disorders studied were much lower than expected, the pattern of AR being more prevalent in $\mathrm{WNH}$ mothers and $\mathrm{AD}$ being more prevalent $\mathrm{BNH}$ mothers was consistent with previous research findings. ${ }^{12} 13$ Additionally, this study did find a higher prevalence of NAA among smokers compared with non-smokers. ${ }^{2}$

This study is unique in that it is the first study to report on atopy and birth outcomes in a population from the Western Hemisphere, particularly from the state of South Carolina, USA. Findings about other risk factors such as smoking, diabetes and hypertension were consistent with previous literature both the prevalence of these risk factors and their effect on the study outcomes. Additionally, we found that mothers with asthma were more likely to suffer from other forms of atopy when compared with mothers without asthma. This suggests that the findings with respect to NAA were reliable even though the prevalence of NAA was inexplicably low in this population. The low prevalence of NAA could be due to geographical variations between the single state explored and other regions in the USA and the rest of the world. There may also be varying practices associated with the diagnosis and treatment of atopic symptoms that are not considered to be as serious as asthma. Although, the prevalence of NAA was low in the study population, the large sample size had over $90 \%$ power to detect a $50 \%$ reduction in risk or a $50 \%$ increase in risk of the outcomes studied.

This study had some limitations which include using information on mothers from a single state, not having information on the severity of each atopic disorder and not having specific information on timing of symptom onset or duration. This study did not assess medication taken by the mother to treat NAA or other conditions that are related to the study outcomes. Additionally, this study could not control for geographical effects which may vary even with a single state and may affect the severity of atopic conditions. Another limitation of this study is the fact that it used a Medicaid database and as such results may not be generalisable to the general population of the state. However, the prevalence of the study outcomes as well as other chronic disorders which are better documented (ie, preterm birth, low birth weight, hypertension and smoking) were consistent with the available rates for the state of South Carolina.

The presence of NAA (AR and/or $\mathrm{AD}$ ) does not affect birth outcomes such as LBW, SGA and PTB among women living in South Carolina, USA. This study highlights that disease morbidity can have wide geographic variations.

Additional studies are needed to establish the pattern of how NAA affects birth outcomes in other cohorts of women such as varying ethnicities and social strata.

Contributors AJ, TM, RSK and DL made substantial contributions to the conception, design of the work, the acquisition of the data, data analysis and the interpretation of results of the data analysis. HMS made substantial contributions to the data analysis, and the interpretation of results of the data analysis.

Competing interests None declared.

Patient consent Detail has been removed from these case descriptions to ensure anonymity. The editors and reviewers have seen the detailed information available and are satisfied that the information backs up the case the authors are making.

Ethics approval University of South Florida Institutional Review Board.

Provenance and peer review Not commissioned; externally peer reviewed.

Data sharing statement No additional data available.

Open Access This is an Open Access article distributed in accordance with the Creative Commons Attribution Non Commercial (CC BY-NC 4.0) license, which permits others to distribute, remix, adapt, build upon this work non-commercially, and license their derivative works on different terms, provided the original work is properly cited and the use is non-commercial. See: http://creativecommons.org/ licenses/by-nc/4.0/

(C) Article author(s) (or their employer(s) unless otherwise stated in the text of the article) 2017. All rights reserved. No commercial use is permitted unless otherwise expressly granted.

\section{REFERENCES}

1. Deckers IA, McLean S, Linssen S, et al. Investigating international time trends in the incidence and prevalence of atopic eczema 19902010: a systematic review of epidemiological studies. PLoS One 2012;7:e39803.

2. Jarvis $D$, Burney P. ABC of allergies. The epidemiology of allergic disease. BMJ 1998;316:607-10.

3. Pawankar R, Canonica GW, Holgate ST, et al. Allergic diseases and asthma: a major global health concern. Curr Opin Allergy Clin Immunol 2012;12:39-41.

4. Simpson BM, Custovic A, Simpson A, et al. NAC Manchester Asthma and Allergy Study (NACMAAS): risk factors for asthma and allergic disorders in adults. Clin Exp Allergy 2001;31:391-9.

5. Bieber T. Atopic Dermatits. N Engl J Med 2008;14:1483-94.

6. American Academy of Allergy Asthma \& Immunology, 2015. retrieved from. http://www.aaaai.org

7. Pawankar R, Canonica GW, Holgate ST, et al. World Allergy Organization (WAO) white book on allergy 2011-2012 executive summary, 2011.

8. Franzese C. Diagnosis of inhalant allergies: patient history and testing. Otolaryngol Clin North Am 2011;44:611-23.

9. Sibbald B, Rink E. Epidemiology of seasonal and perennial rhinitis: clinical presentation and medical history. Thorax 1991;46:895-901.

10. Karmaus W, Botezan C. Does a higher number of siblings protect against the development of allergy and asthma? A review. $J$ Epidemiol Community Health 2002;56:209-17.

11. Rona RJ, Duran-Tauleria E, Chinn S. Family size, atopic disorders in parents, asthma in children, and ethnicity. J Allergy Clin Immunol 1997;99:454-60.

12. Hjern A, Haglund B, Hedlin G. Ethnicity, childhood environment and atopic disorder. Clin Exp Allergy 2000;30:521-8.

13. Williams $\mathrm{H}$, Robertson $\mathrm{C}$, Stewart $\mathrm{A}$, et al. Worldwide variations in the prevalence of symptoms of atopic eczema in the International Study of Asthma and Allergies in Childhood. J Allergy Clin Immunol 1999;103:125-38.

14. Jackson KD, Howie LD, Akinbami LJ. Trends in allergic conditions among children: United States, 1997-2011. NCHS Data Brief 2013;121:1-8.

15. Schäfer T, Ruhdorfer S, Weigl L, et al. School education and allergic sensitization in adults. Allergy 2001;56:1206-10.

16. Savilahti E, Siltanen M, Pekkanen J, et al. Mothers of very low birth weight infants have less atopy than mothers of full-term infants. Clin Exp Allergy 2004;34:1851-4. 
17. Somoskövi A, Bártfai Z, Tamási L, et al. Population-based casecontrol study of allergic rhinitis during pregnancy for birth outcomes. Eur J Obstet Gynecol Reprod Biol 2007;131:21-7.

18. Trønnes H, Wilcox AJ, Markestad T, et al. Associations of maternal atopic diseases with adverse pregnancy outcomes: a national cohort study. Paediatr Perinat Epidemiol 2014;28:489-97.

19. Croen LA, Grether JK, Yoshida CK, et al. Maternal autoimmune diseases, asthma and allergies, and childhood autism spectrum disorders: a case-control study. Arch Pediatr Adolesc Med 2005;159:151.

20. Amoudruz P, Holmlund U, Malmström V, et al. Neonatal immune responses to microbial stimuli: is there an influence of maternal allergy?. J Allergy Clin Immunol 2005;115:1304-10.

21. Krauss-Etschmann $S$, Hartl D, Heinrich J, et al. Association between levels of Toll-like receptors 2 and 4 and CD14 mRNA and allergy in pregnant women and their offspring. Clin Immunol 2006;118:292-9.

22. Pali-Schöll I, Renz H, Jensen-Jarolim E. Update on allergies in pregnancy, lactation, and early childhood. J Allergy Clin Immunol 2009;123:1012-21.
23. Reece P, Thanendran A, Crawford L, et al. Maternal allergy modulates cord blood hematopoietic progenitor Toll-like receptor expression and function. J Allergy Clin Immunol 2011;127:447-53.

24. StataCorp. Stata Statistical Software: Release 12. College Station, TX: StataCorp, 2011.

25. DHEC Bureau of Community Health and Chronic Disease Prevention. Asthma in South Carolina. South Carolina: DHEC Bureau of Community Health and Chronic Disease Prevention, 2015.

26. Greiner AN, Hellings PW, Rotiroti G, et al. Allergic rhinitis. The Lancet 2011;378:2112-22.

27. Mercer MJ, Joubert G, Ehrlich RI, et al. Socioeconomic status and prevalence of allergic rhinitis and atopic eczema symptoms in young adolescents. Pediatr Allergy Immunol 2004;15:234-41.

28. Bergmann RL, Edenharter G, Bergmann KE, et al. Socioeconomic status is a risk factor for allergy in parents but not in their children. Clin Exp Allergy 2000;30:1740-5.

29. Quillen DM, Feller DB. Diagnosing rhinitis: allergic vs. nonallergic. Am Fam Physician 2006;73:1583-90. 